\title{
Terahertz-induced Kerr effect in amorphous chalcogenide glasses
}

Zalkovskij, Maksim; Strikwerda, Andrew; Iwaszczuk, Krzysztof; Popescu, A.; Savastru, A.; Malureanu, Radu; Lavrinenko, Andrei; Jepsen, Peter Und

Published in:

Applied Physics Letters

Link to article, DOI:

$10.1063 / 1.4832825$

Publication date:

2013

Document Version

Publisher's PDF, also known as Version of record

Link back to DTU Orbit

Citation (APA):

Zalkovskij, M., Strikwerda, A., Iwaszczuk, K., Popescu, A., Savastru, A., Malureanu, R., Lavrinenko, A., \& Jepsen, P. U. (2013). Terahertz-induced Kerr effect in amorphous chalcogenide glasses. Applied Physics Letters, 103(22), [221102]. https://doi.org/10.1063/1.4832825

\section{General rights}

Copyright and moral rights for the publications made accessible in the public portal are retained by the authors and/or other copyright owners and it is a condition of accessing publications that users recognise and abide by the legal requirements associated with these rights.

- Users may download and print one copy of any publication from the public portal for the purpose of private study or research.

- You may not further distribute the material or use it for any profit-making activity or commercial gain

- You may freely distribute the URL identifying the publication in the public portal 


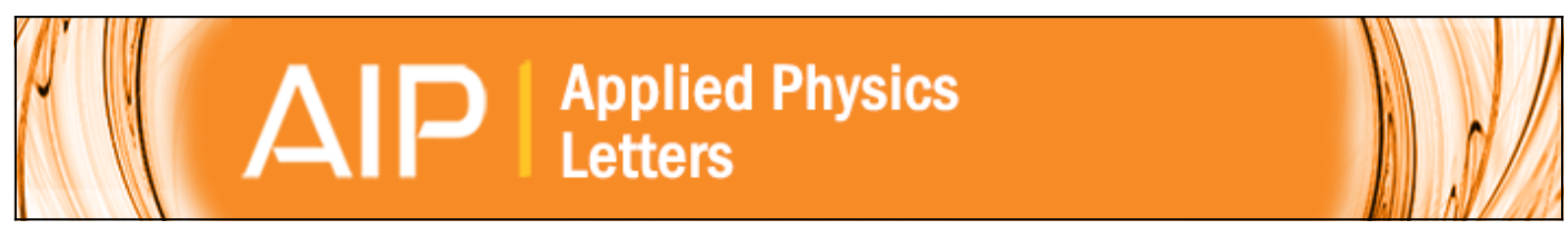

\section{Terahertz-induced Kerr effect in amorphous chalcogenide glasses}

M. Zalkovskij, A. C. Strikwerda, K. Iwaszczuk, A. Popescu, D. Savastru, R. Malureanu, A. V. Lavrinenko, and P. U. Jepsen

Citation: Applied Physics Letters 103, 221102 (2013); doi: 10.1063/1.4832825

View online: http://dx.doi.org/10.1063/1.4832825

View Table of Contents: http://scitation.aip.org/content/aip/journal/apl/103/22?ver=pdfcov

Published by the AIP Publishing

\section{Over 700 papers \& presentations on}

multiphysics simulation vew now

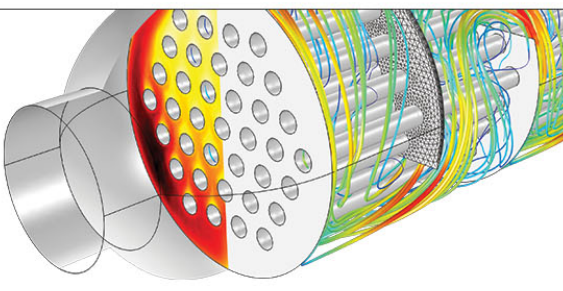




\title{
Terahertz-induced Kerr effect in amorphous chalcogenide glasses
}

\author{
M. Zalkovskij, ${ }^{1, a)}$ A. C. Strikwerda, ${ }^{1}$ K. Iwaszczuk, ${ }^{1}$ A. Popescu, ${ }^{2}$ D. Savastru, ${ }^{2}$ \\ R. Malureanu, ${ }^{1}$ A. V. Lavrinenko, ${ }^{1}$ and P. U. Jepsen ${ }^{1}$ \\ ${ }^{1}$ Department of Photonics Engineering, Technical University of Denmark, Kgs. Lyngby, DK-2800, Denmark \\ ${ }^{2}$ National Institute of R\&D for Optoelectronics INOE 2000, Bucharest, Romania
}

(Received 18 September 2013; accepted 7 November 2013; published online 25 November 2013)

\begin{abstract}
We have investigated the terahertz-induced third-order (Kerr) nonlinear optical properties of the amorphous chalcogenide glasses $\mathrm{As}_{2} \mathrm{~S}_{3}$ and $\mathrm{As}_{2} \mathrm{Se}_{3}$. Chalcogenide glasses are known for their high optical Kerr nonlinearities which can be several hundred times greater than those of fused silica. We use high-intensity, single-cycle terahertz pulses with a maximum electrical field strength exceeding $400 \mathrm{kV} / \mathrm{cm}$ and frequency content from 0.2 to $3.0 \mathrm{THz}$. By optical Kerr-gate sampling, we measured the terahertz-induced nonlinear refractive indices at $800 \mathrm{~nm}$ to be $n_{2}=1.746 \times 10^{-14}$ $\mathrm{cm}^{2} / \mathrm{W}$ for $\mathrm{As}_{2} \mathrm{~S}_{3}$ and $n_{2}=3.440 \times 10^{-14} \mathrm{~cm}^{2} / \mathrm{W}$ for $\mathrm{As}_{2} \mathrm{Se}_{3}$. (C) 2013 AIP Publishing LLC. [http://dx.doi.org/10.1063/1.4832825]
\end{abstract}

Terahertz $(\mathrm{THz})$ technology has the potential for application in a broad range of fields, e.g., biology, medicine, ${ }^{1}$ communication, and in the space-, defense-, and semiconductor-industry. ${ }^{2,3}$ While there has been tremendous progress in the development of $\mathrm{THz}$ sources, detectors, and passive linear components, many applications, such as ultrafast alloptical signal processing, require more versatile, nonlinear components. To construct these nonlinear components, materials with nonlinear interactions between the $\mathrm{THz}$ electric field and matter must be identified, developed, and quantified.

Chalcogenide glasses, first reported six decades ago, ${ }^{4}$ have attracted significant attention in recent years due to their unique properties such as high refractive index, midinfrared transparency, and very large third-order (Kerr) nonlinearity. ${ }^{5}$ Their large nonlinearities in the optical, near-, and mid-infrared regions have made them promising candidates for fast nonlinear optical devices. ${ }^{6}$

The measurement of the THz-induced optical Kerr effect in solid-state materials has traditionally been hampered by a lack of high intensity $\mathrm{THz}$ sources. However, the recent introduction of tilted pulse front $\mathrm{THz}$ generation in lithium niobate $\left(\mathrm{LiNbO}_{3}\right)^{7}$ now makes $\mathrm{THz}$ field strengths of the order of $1 \mathrm{MV} / \mathrm{cm}$ available. ${ }^{8,9}$ Such pulses were recently applied for the investigation of the THz-induced optical Kerr effect in liquids ${ }^{10}$ and in relaxor ferroelectrics. ${ }^{11}$

In this paper, we report the observation of the THzinduced optical Kerr effect in two bulk, amorphous chalcogenide glasses, $\mathrm{As}_{2} \mathrm{~S}_{3}$ and $\mathrm{As}_{2} \mathrm{Se}_{3}$, and determine their third-order nonlinear coefficients. Both glasses have become very popular in optics due to their high nonlinear coefficients $^{12-15}$ and flexibility towards micro- and nano-fabrication. ${ }^{16-18}$

Our experimental setup is shown schematically in Fig. 1(a). Briefly, an amplified femtosecond laser system (pulse energy $3.5 \mathrm{~mJ}$, duration $100 \mathrm{fs}$, center wavelength $800 \mathrm{~nm}$ ) drives a standard tilted pulse front scheme for generation of intense $\mathrm{THz}$ pulses in $\mathrm{LiNbO}_{3}{ }^{8}$ The generated $\mathrm{THz}$ beam is tightly focused onto the sample by a combination of

${ }^{\text {a)} E l e c t r o n i c ~ m a i l: ~ m z a l @ f o t o n i k . d t u . d k . ~}$ off-axis paraboloidal mirrors. A small portion of the $800 \mathrm{~nm}$ laser beam is picked off prior to the $\mathrm{LiNbO}_{3}$ crystal and used to sample the THz-induced birefringence in the chalcogenide samples $\left(0.716 \mathrm{~mm}\right.$ thick $\mathrm{As}_{2} \mathrm{~S}_{3}$ and $1.059 \mathrm{~mm}$ thick $\left.\mathrm{As}_{2} \mathrm{Se}_{3}\right)$ in a Kerr-gate sampling configuration. The temporal shape of the Kerr signal is recorded by gradually delaying the optical probe beam with respect to the $\mathrm{THz}$ beam while monitoring the THz-induced birefringence. In order to determine the absolute field strength of the $\mathrm{THz}$ pulses, the chalcogenide samples were replaced by an $300 \mu \mathrm{m}$ thick electro-optic gallium phosphide $(\mathrm{GaP})$ crystal so that the temporal profile of the $\mathrm{THz}$ pulses could be measured by electro-optic (EO) sampling. ${ }^{19-21}$ The detected THz pulse is shown in Fig. 1(b) and has a peak electric field strength of $400 \pm 10 \mathrm{kV} / \mathrm{cm}$. This number is a minimum value, and is determined by EO sampling via the recorded phase retardation and its relation to the absolute electric field strength, $\Delta \phi=\omega L n_{0}^{3} r_{41} E_{T H z} / c$, where $r_{41}$ is the electro-optic coefficient, $n_{0}$ is the refractive index at the probe wavelength $(\lambda=2 \pi / \omega)$, and $L$ is the length of $\mathrm{GaP}$ crystal. ${ }^{22}$ During electro-optic sampling, the $\mathrm{THz}$ signal was attenuated by a number of high-resistivity silicon wafers in order to avoid over-rotation, and the attenuation from the wafers was subsequently accounted for in the field calibration. The frequency content spans the $0.05-3 \mathrm{THz}$ region with $84 \%$ of the pulse energy concentrated within $0.2-1.0$ THz. The alignment, and thus spatial overlap of generation and probe beam paths, was unchanged during both the Kerr characterization of the chalcogenide samples and the electro-optic sampling of the pulse shape.

In the Kerr-gate experiment, the probe beam is initially polarized at $45^{\circ}$ with respect to the $\mathrm{THz}$ pulse polarization while in EO sampling experiments the probe beam is parallel with $\mathrm{THz}$ pulse polarization. The THz-induced phase difference, $\Delta \phi$, between the two polarization components parallel and perpendicular to the $\mathrm{THz}$ field polarization is detected as a differential voltage relative to the unperturbed signal on each photodiode. This signal, which is measured after propagation through a quarter-wave plate and polarizing beam splitter in a standard balanced scheme, ${ }^{10}$ can be modeled as $\Delta V / V_{0}=\sin (\Delta \phi)=\sin (\Delta n \omega L / c)$. Here, $\Delta n$ is the THzinduced modulation of the refractive index, $\omega$ is the angular 

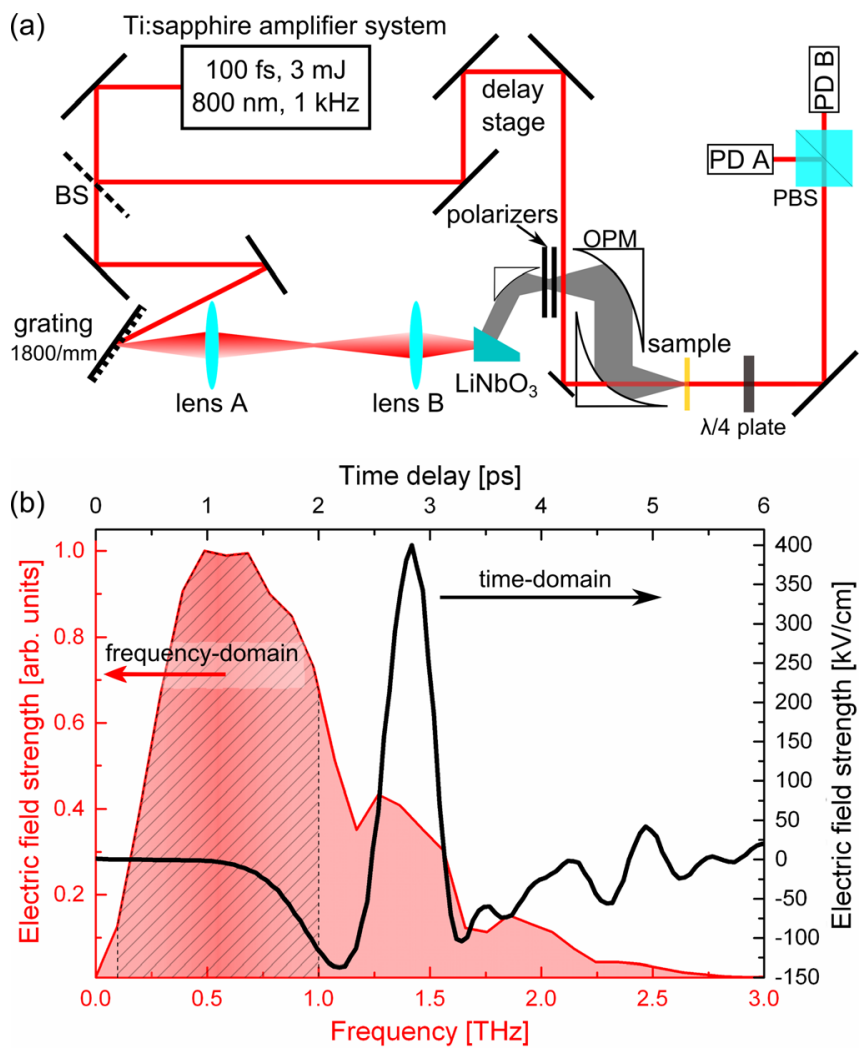

FIG. 1. (a) A schematic illustration of the $\mathrm{LiNbO}_{3}$ THz-TDS system used for $\mathrm{THz}$ Kerr measurements. (b) $\mathrm{THz}$ pulse in time- (black curve) and frequency-domain (red curve). $84 \%$ of the pulse energy is concentrated between 0.2 and $1.0 \mathrm{THz}$, and is highlighted by dashed area. (BS) beam splitter, (OPM) optical parabolic mirror, (PD) photodiode, and (PBS) polarizing beam splitter.

frequency of the probe beam, and $L$ is the effective propagation length in the crystal. The probe beam intensity was kept at a low level to avoid any photodamage to the samples.

The recorded Kerr probe signals in $\mathrm{As}_{2} \mathrm{~S}_{3}$ and $\mathrm{As}_{2} \mathrm{Se}_{3}$ at varying $\mathrm{THz}$ field strengths are shown in Fig. 2. The field strength was attenuated by a pair of wire grid polarizers placed immediately after the first paraboloidal mirror. To verify that the samples were not damaged during the characterization, each sample was measured at the highest field strength both at the beginning and at the end of the measurement series. The results were then compared to confirm that the samples had not been damaged during the characterization. As expected, the recorded signal increases with the $\mathrm{THz}$ pulse strength. At a field strength of $47 \mathrm{kV} / \mathrm{cm}$, the THz-induced signal is barely noticeable but it grows significantly at higher field strengths. We used a $1 \mathrm{~mm}$ thick bulk silica glass sample as a reference. Even with the full field strength $(400 \mathrm{kV} / \mathrm{cm})$, no $\mathrm{THz}$-induced birefringence was observed due to the very small third-order nonlinearity of silica compared to $\mathrm{As}_{2} \mathrm{~S}_{3}$ and $\mathrm{As}_{2} \mathrm{Se}_{3}{ }^{13}$

For both the chalcogenide glasses, we observe that the temporal shape of the THz-induced Kerr signal closely follows the intensity profile of the $\mathrm{THz}$ pulse (dashed, red curves). This is indicative of a very fast nonlinear response for the two glasses, and is typical for nonresonant excitation. In contrast to some liquid samples, such as $\mathrm{CH}_{2} \mathrm{I}_{2},{ }^{10}$ where the relaxation time can be rather long, there are no rotational dynamics of molecules in solid glasses. In the case of $\mathrm{As}_{2} \mathrm{~S}_{3}$,
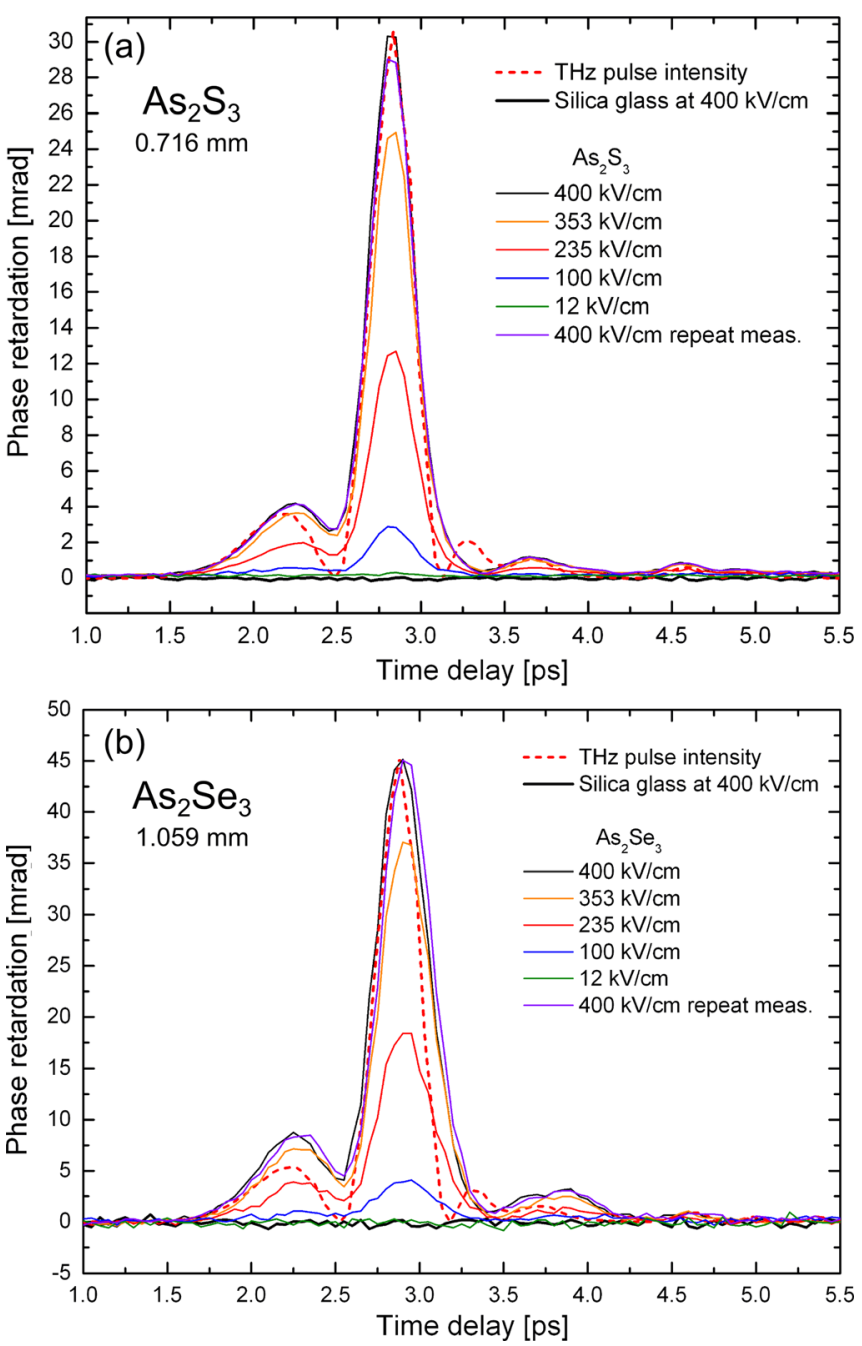

FIG. 2. The THz-induced birefringence in (a) $\mathrm{As}_{2} \mathrm{~S}_{3}(0.716 \mathrm{~mm}$ ) and (b) $\mathrm{As}_{2} \mathrm{Se}_{3}(1.059 \mathrm{~mm})$ bulk samples as a function of the peak $\mathrm{THz}$ field strength. The intensity of the $\mathrm{THz}$ pulse normalized to the maximum recorded signal is indicated by the dashed, red curve. The black curve is for a $1 \mathrm{~mm}$ thick silica glass sample measured with $400 \mathrm{kV} / \mathrm{cm}$ field strength for comparison.

the THz-induced signal instantly responds to the changes in the intensity profile of the $\mathrm{THz}$ pulse, as there is good phase matching between the $\mathrm{THz}$ wave and probe beam in the glass. There is a slight indication of a delayed response from $\mathrm{As}_{2} \mathrm{Se}_{3}$. However, this might be due to the large velocity mismatch between the $\mathrm{THz}$ field and the optical probe, as will be discussed further below.

The analysis of the peak values of the THz-induced signal in glasses reveals a standard third-order nonlinear behavior, shown in Fig. 3. For the small values of the phase retardation observed here, the recorded values are accurately fitted by a quadratic fit $\Delta V / V_{0} \approx \Delta \phi=k \times E^{2}$, where $k$ is a constant and $E$ is the electrical field strength. This demonstrates that the observed THz-induced signals in the chalcogenide samples are due to the Kerr effect $\left(\Delta n=\lambda K E^{2}\right)$, where $\Delta n$ is the change in the refractive index, $\lambda$ is the wavelength, and $K$ is the Kerr constant. The nonlinear refractive index can be written as $n_{2}=\Delta n / I$ where $I$ is the intensity of the $\mathrm{THz}$ pulse averaged over either the propagation length in the glass or the physical length of the sample, whichever is shorter. 


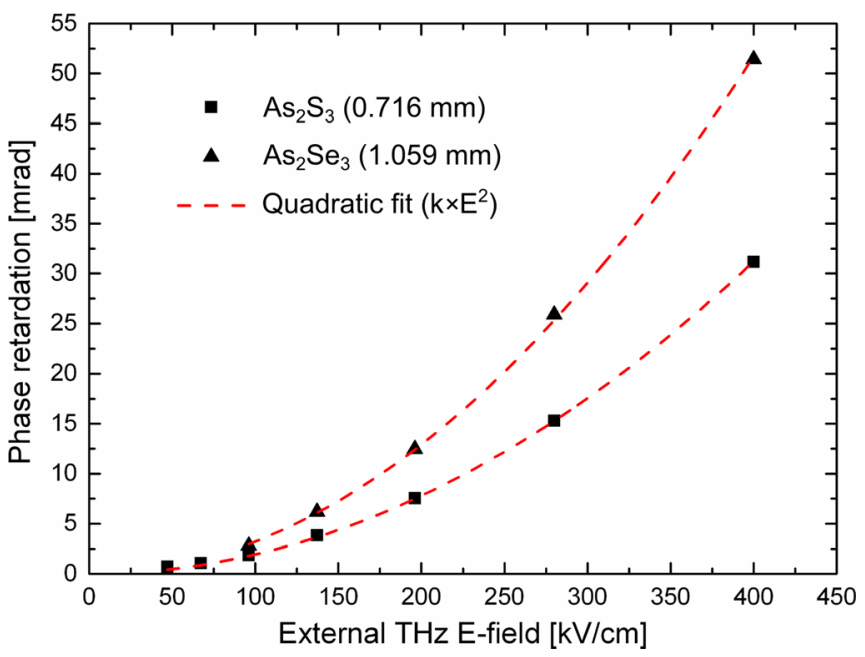

FIG. 3. The peak values of the THz-induced Kerr signals for $\mathrm{As}_{2} \mathrm{~S}_{3}$ (squares) and $\mathrm{As}_{2} \mathrm{Se}_{3}$ (triangles). The red, dashed curves are quadratic fits to the measured data points.

As we have previously reported, chalcogenide glass has the universal characteristics of an amorphous system at lower terahertz frequencies with a monotonous increase of the absorption coefficient. ${ }^{23}$ However, crystalline phases may exist within the amorphous matrix. To verify that our samples are truly amorphous, we performed the Kerr measurements with the full electrical $\mathrm{THz}$ field strength at different orientation angles of the $\mathrm{As}_{2} \mathrm{~S}_{3}$ sample (Fig. 4). No significant change in the Kerr signal is observed when the sample was rotated from $0^{\circ}$ to $90^{\circ}$.

To determine the magnitude of the Kerr effect, we measured both the refractive index and absorption coefficient of the two chalcogenide glasses in the terahertz range with a Picometrix T-Ray 4000 THz-TDS system, as shown in Fig. 5 . The refractive indices for both glasses in the frequency range $0.2-1.0 \mathrm{THz}$ are nearly constant $\left(2.80\right.$ for $\mathrm{As}_{2} \mathrm{~S}_{3}$ and 2.86 for $\mathrm{As}_{2} \mathrm{Se}_{3}$ ). The slightly higher $\mathrm{As}_{2} \mathrm{Se}_{3}$ refractive index can be explained by the higher density of $\mathrm{As}_{2} \mathrm{Se}_{3}$ $\left(4.75 \mathrm{~g} / \mathrm{cm}^{3}\right)$ compared to $\mathrm{As}_{2} \mathrm{~S}_{3}\left(3.42 \mathrm{~g} / \mathrm{cm}^{3}\right)$. The group indices for the $800-\mathrm{nm}$ optical probe beam are $2.76^{24}$ and

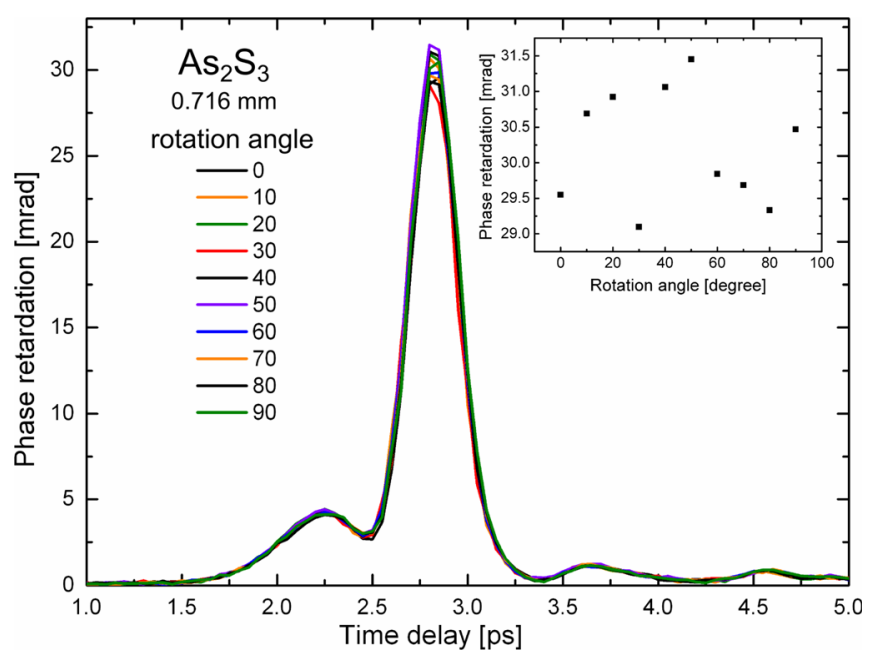

FIG. 4. The THz-induced Kerr signal as a function of $\mathrm{As}_{2} \mathrm{~S}_{3}$ rotation angle at a $\mathrm{THz}$ electric field strength of $400 \mathrm{kV} / \mathrm{cm}$. The rotation spans from $0^{\circ}$ to $90^{\circ}$ in steps of $10^{\circ}$.

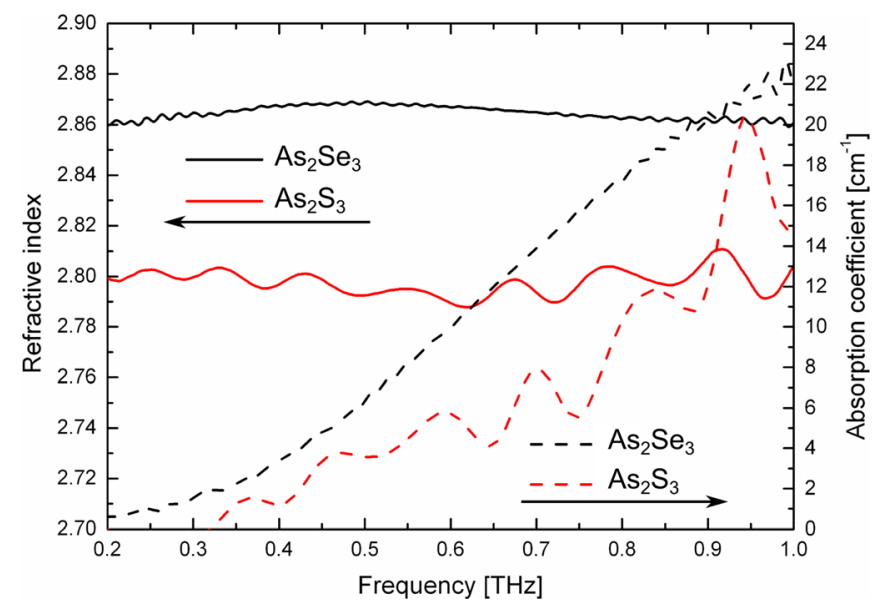

FIG. 5. The refractive index (solid curves) and absorption coefficient (dashed curves) for $\mathrm{As}_{2} \mathrm{~S}_{3}$ (red) and $\mathrm{As}_{2} \mathrm{Se}_{3}$ (black) samples as measured by THz-TDS.

$3.65^{25}$ for $\mathrm{As}_{2} \mathrm{~S}_{3}$ and $\mathrm{As}_{2} \mathrm{Se}_{3}$, respectively. The resulting velocity mismatch between the optical probe beam and the $\mathrm{THz}$ pulse may result in smearing of the recorded Kerr signals, and consequently a slight underestimation of the extracted nonlinear coefficient. This effect will be most profound for $\mathrm{As}_{2} \mathrm{Se}_{3}$. The absorption coefficient monotonously increases from nearly zero to approximately $20-22 \mathrm{~cm}^{-1}$ for both samples between $0.2 \mathrm{THz}$ and $1.0 \mathrm{THz}$. This behavior is universal for a wide range of glasses, and confirms the amorphous nature of chalcogenide glasses at low $\mathrm{THz}$ frequencies. $^{23,26}$ For further analysis, we calculated the weighted average of the absorption coefficient over the pulse spectrum in the range $0.2-1.0 \mathrm{THz}$. This range contains $84 \%$ of the total intensity of the $\mathrm{THz}$ pulse (see Fig. 1(b)). Averaged absorption coefficients $\alpha=6.2 \mathrm{~cm}^{-1}$ and $10.8 \mathrm{~cm}^{-1}$ are found for $\mathrm{As}_{2} \mathrm{~S}_{3}$ and $\mathrm{As}_{2} \mathrm{Se}_{3}$ with a characteristic penetration depth $\left(L_{a b s}=1 / \alpha\right)$ of $1.61 \mathrm{~mm}$ and $0.93 \mathrm{~mm}$, respectively. We use these values to calculate the local $\mathrm{THz}$ field inside the bulk sample taking absorption and Fresnel transmission coefficients into account.

We determined the $\mathrm{THz}$-induced nonlinear refractive indices $n_{2}=1.746 \times 10^{-14} \mathrm{~cm}^{2} / \mathrm{W}$ and $n_{2}=3.440 \times 10^{-14}$ $\mathrm{cm}^{2} / \mathrm{W}$ at $800 \mathrm{~nm}$ for $\mathrm{As}_{2} \mathrm{~S}_{3}$ and $\mathrm{As}_{2} \mathrm{Se}_{3}$, respectively, in Table I. The larger $\mathrm{THz}$ Kerr effect for $\mathrm{As}_{2} \mathrm{Se}_{3}$ is consistent with the significantly larger third-order nonlinear optical coefficient in $\mathrm{As}_{2} \mathrm{Se}_{3}$ as compared to $\mathrm{As}_{2} \mathrm{~S}_{3}$. The measured

TABLE I. THz-induced optical parameters of $\mathrm{As}_{2} \mathrm{~S}_{3}$ and $\mathrm{As}_{2} \mathrm{Se}_{3}$ glasses.

\begin{tabular}{lcc}
\hline \hline & $\mathrm{As}_{2} \mathrm{~S}_{3}$ & $\mathrm{As}_{2} \mathrm{Se}_{3}$ \\
\hline$\Delta n^{\mathrm{a}}\left[10^{-6}\right]$ & 5.34 & 6.30 \\
$n_{2}{ }^{\mathrm{b}}\left[10^{-14} \mathrm{~cm}^{2} / \mathrm{W}\right]$ & $1.75 \pm 0.09$ & $3.44 \pm 0.17$ \\
$n_{2, \text { nir }}{ }^{\mathrm{c}}\left[10^{-14} \mathrm{~cm}^{2} / \mathrm{W}\right]$ & 2.5 & 11.4 \\
$\chi^{(3) \mathrm{d}}\left[10^{-20} \mathrm{~m}^{2} / \mathrm{V}^{2}\right]$ & $4.84 \pm 0.24$ & $9.96 \pm 0.50$ \\
$I_{\text {peak }}{ }^{\mathrm{e}}\left[10^{8} \mathrm{~W} / \mathrm{cm}^{2}\right]$ & $3.06 \pm 0.15$ & $1.83 \pm 0.09$ \\
\hline
\end{tabular}

${ }^{\mathrm{a}} \Delta n$ is the modulation of the refractive index.

${ }^{\mathrm{b}} n_{2}$ is the nonlinear refractive index.

${ }^{\mathrm{c}} n_{2, n i r}$ is the nonlinear refractive index measured at near infrared. ${ }^{12,14}$

${ }^{d} \chi^{(3)}$ is the nonlinear susceptibility $\left(\chi^{(3)}=\frac{4}{3} \times \varepsilon_{0} c \times n_{0}^{2} n_{2}\right.$, where $n_{0}$ is linear refractive index).

${ }^{\mathrm{e}} I_{\text {peak }}$ is the peak intensity averaged through samples. 
nonlinear refractive index for $\mathrm{As}_{2} \mathrm{~S}_{3}$ is comparable with the values that were reported for the near infrared, $n_{2, \text { nir }}=2.5$ $\times 10^{-14} \mathrm{~cm}^{2} / \mathrm{W},{ }^{12}$ while that of $\mathrm{As}_{2} \mathrm{Se}_{3}$ is approximately 3 times lower, $n_{2, \text { nir }}=11.4 \times 10^{-14} \mathrm{~cm}^{2} / \mathrm{W}^{14}$

In summary, we have reported the observation of the THz-induced optical Kerr effect in solid materials, using intense $\mathrm{THz}$ pulses of up to $400 \mathrm{kV} / \mathrm{cm}$. Both chalcogenide samples, $\mathrm{As}_{2} \mathrm{~S}_{3}$ and $\mathrm{As}_{2} \mathrm{Se}_{3}$, reveal large nonlinear refractive indices. Furthermore, due to the nonresonant nature of the third-order nonlinearity in the amorphous glasses, a near-instantaneous (faster than the time resolution of the experiment) response of the Kerr signal was observed.

Financial support from the Danish Research Council for Technology and Production Sciences through Project No. 09-070397-FTP (THz-COW) and Project No. 11-106748FTP (HI-TERA) is acknowledged.

${ }^{1}$ P. H. Siegel, IEEE Trans. Microwave Theory Tech. 52, 2438 (2004).

${ }^{2}$ P. U. Jepsen, D. G. Cooke, and M. Koch, Laser Photonics Rev. 5, 124 (2011).

${ }^{3}$ M. Tonouchi, Nat. Photonics 1, 97 (2007).

${ }^{4}$ R. Frerichs, J. Opt. Soc. Am. 43, 1153 (1953).

${ }^{5}$ A. Zakery, J. Non-Cryst. Solids 330, 1 (2003).

${ }^{6}$ B. J. Eggleton, B. Luther-Davies, and K. Richardson, Nat. Photonics 5, 141 (2011).

${ }^{7}$ J. Hebling, G. Almasi, I. Kozma, and J. Kuhl, Opt. Express 10, 1161 (2002).

${ }^{8}$ H. Hirori, A. Doi, F. Blanchard, and K. Tanaka, Appl. Phys. Lett. 98, 091106 (2011).
${ }^{9}$ S.-W. Huang, E. Granados, W. R. Huang, K.-H. Hong, L. E. Zapata, and F. X. Kärtner, Opt. Lett. 38, 796 (2013).

${ }^{10}$ M. C. Hoffmann, N. C. Brandt, H. Y. Hwang, K.-L. Yeh, and K. A. Nelson, Appl. Phys. Lett. 95, 231105 (2009).

${ }^{11}$ H. Y. Hwang, M. C. Hoffmann, N. C. Brandt, and K. A. Nelson, International Conference on Ultrafast Phenomena (2010).

${ }^{12}$ F. Smektala, C. Quemard, L. Leneindre, J. Lucas, A. Barthélémy, and C. De Angelis, J. Non-Cryst. Solids 239, 139 (1998).

${ }^{13}$ J. M. Harbold, F. O. Ilday, F. W. Wise, J. S. Sanghera, V. Q. Nguyen, L. B. Shaw, and I. D. Aggarwal, Opt. Lett. 27, 119 (2002).

${ }^{14}$ K. Ogusu, J. Yamasaki, S. Maeda, M. Kitao, and M. Minakata, Opt. Lett. 29, 265 (2004).

${ }^{15}$ H. Kobayashi, H. Kanbara, M. Koga, and K. Kubodera, J. Appl. Phys. 74, 3683 (1993).

${ }^{16}$ S. Madden, D.-Y. Choi, D. A. Bulla, A. V. Rode, B. Luther-Davies, V. G. Ta'eed, M. D. Pelusi, and B. J. Eggleton, Opt. Express 15, 14414 (2007).

${ }^{17}$ S. Wong, M. Deubel, F. Pérez-Willard, S. John, G. A. Ozin, M. Wegener, and G. von Freymann, Adv. Mater. 18, 265 (2006).

${ }^{18}$ T. Han, S. Madden, D. Bulla, and B. Luther-davies, Opt. Express 18, 19286 (2010).

${ }^{19}$ Q. Wu and X.-C. Zhang, Appl. Phys. Lett. 67, 3523 (1995).

${ }^{20}$ A. Nahata, D. H. Auston, T. F. Heinz, and C. Wu, Appl. Phys. Lett. 68, 150 (1996).

${ }^{21}$ P. Jepsen, C. Winnewisser, M. Schall, V. Schyja, S. Keiding, and H. Helm, Phys. Rev. E 53, R3052 (1996).

${ }^{22}$ Y.-S. Lee, Principles of Terahertz Science and Technology (Springer, Boston, MA, 2009).

${ }^{23}$ M. Zalkovskij, C. Zoffmann Bisgaard, A. Novitsky, R. Malureanu, D. Savastru, A. Popescu, P. Uhd Jepsen, and A. V. Lavrinenko, Appl. Phys. Lett. 100, 031901 (2012).

${ }^{24}$ W. S. Rodney, I. H. Malitson, and T. A. King, J. Opt. Soc. Am. 48, 633 (1958).

${ }^{25}$ C. Corrales, J. B. Ramírez-Malo, J. Fernández-Peña, P. Villares, R. Swanepoel, and E. Márquez, Appl. Opt. 34, 7907 (1995).

${ }^{26}$ S. Taraskin, S. Simdyankin, S. Elliott, J. Neilson, and T. Lo, Phys. Rev. Lett. 97, 055504 (2006). 